ORIGINAL ARTICLE

\title{
Can we abolish skull $x$ rays for head injury?
}

M J Reed, J G Browning, A G Wilkinson, T Beattie

Arch Dis Child 2005;90:859-864. doi: 10.1136/adc.2004.053603

Objectives: To assess the effect of a change in skull $x$ ray policy on the rate of admission, use of computed tomography $(\mathrm{CT})$, radiation dose per head injury, and detection of intracranial injuries; and to compare the characteristics of patients with normal and abnormal head CT.

Design: Retrospective cohort study.

Setting: UK paediatric teaching hospital emergency department.

See end of article for authors' affiliations

....................

Correspondence to: Matthew J Reed, Accident and Emergency

Department, Royal Hospital for Sick Children, Sciennes Road, Edinburgh, UK; mattreed1@hotmail. com

Accepted

11 September 2004

Published Online First 25 April 2005
Patients: 1535 patients aged between 1 and 14 years with a head injury presenting to the emergency department between 1 August 1998 and 31 July 1999 (control period), and 1867 presenting between 1 August 2002 and 31 July 2003 (first year of new skull $x$ ray policy).

Intervention: Hospital notes and computer systems were analysed and data were collected on all patients presenting with a head injury.

Results: The abolition of skull $x$ rays in children aged over 1 year prevented about 400 normal skull $x$ rays being undertaken in period 2. The percentage of children undergoing CT rose from $1.0 \%$ to $2.1 \%$ with no change in the positive $\mathrm{CT}$ pick up rate $(25.6 \%$ v $25.0 \%)$. There was no significant change in admission rate $(10.9 \%$ v $10.1 \%)$, and a slight decrease in the radiation dose per head injury $(0.042 \mathrm{mSv}$ compared to $0.045 \mathrm{mSv})$.

Conclusions: Skull $x$ rays can be abandoned in children aged 1 to 14 without a significant increase in admission rate, radiation dose per head injury, or missed intracranial injury. The mechanism and history of the injury and a reduced Glasgow coma scale are probably the most important indicators of significant head injury in children.
$\mathrm{O}$ ne million patients are treated annually in United Kingdom emergency departments for head injury. ${ }^{1}$ Children under the age of 16 years make up one half of these. ${ }^{2}$ Forty five per cent of these childhood injuries occur in those under 5 years of age, ${ }^{3}$ most being minor. There are 4011 emergency department attendances, 400 admissions, and 5.3 deaths per 100000 children per year. ${ }^{4}$ Head injuries contribute to $10 \%$ of childhood hospital admissions (about 50000 per year in the UK), ${ }^{5}$ and they are one of the leading causes of developed world trauma deaths, accounting for $15 \%$ of fatalities between the ages of 1 and $15 .^{6}$

Present paediatric guidelines differ in their emphasis on the use of skull $x$ rays. National Institute for Clinical Effectiveness (NICE) guidelines suggest that skull $x$ rays have a role combined with high quality inpatient observation where computed tomography (CT) is not available. ${ }^{7}$ Scottish Intercollegiate Guideline Network (SIGN) guidelines place more emphasis on skull $x$ rays where there are risk factors for fracture or intracranial injury, although they acknowledge that skull fractures in children are less commonly associated with intracranial injury, and therefore their detection is less helpful than in the adult population. ${ }^{8}$ Head injury guidelines from North America omit skull $x$ rays, and CT is the predominant scanning mode. In the USA, up to $60 \%$ of head injured patients undergo CT, with a resultant low positivity rate of between $5 \%$ and $10 \%$. Less than $30 \%$ of those with intracranial abnormalities go on to require neurosurgical intervention. ${ }^{9}$

Between $23 \%$ and $50 \%$ of skull fractures are missed by junior doctors, ${ }^{10}$ and there are many false positive diagnoses. The presence of a skull fracture has previously been suggested to hugely increase the risk of an intracranial injury. ${ }^{112}$ However in children, severe intracranial injury can occur in the absence of a skull fracture. ${ }^{10}$

Our emergency department head injury policy was revised in 1999 to reduce the emphasis on skull $x$ rays, and to restrict the ordering of them to those aged under 1 year (infants), whom we believe are a special population. They are extremely difficult to assess for symptoms and signs of head injury and they suffer a much higher incidence of non-accidental injury (NAI). This study was therefore restricted to children between the ages of 1 and 14. The revision of our head injury policy gave us a unique opportunity to assess the impact of the abolition of skull $x$ rays on the management of paediatric head injured patients.

There were three main aims to our study: first, to assess the effect of a change in skull $x$ ray policy on the rate of admission, CT imaging, radiation dose per head injury, and detection of intracranial injuries in a paediatric emergency department; second, to compare the characteristics of patients meeting criteria for CT scanning with a group matched for age, triage category, and sex; and third, to compare the characteristics of patients with normal and abnormal head CT.

\section{DESIGN}

This study was a retrospective cohort study conducted in the dedicated paediatric emergency department of a United Kingdom teaching hospital. The departmental head injury policy was revised in 1999 to restrict the ordering of skull $x$ rays to those aged under 1 year (table 1 ).

For the initial part of the study, the emergency department computers were interrogated and notes were retrieved for all patients aged over 1 year and under 14 years presenting within two periods. Period 1 was between 1 August 1998 and 31 July 1999, and period 2 was between 1 August 2002 and 31 July 2003. The first period was chosen as it represents the last full year before the revision of the departmental head injury policy, and the latter period as it represents the most

Abbreviations: NAl, non-accidental injury; NICE, National Institute for Clinical Effectiveness; SIGN, Scottish Intercollegiate Guideline Network 
recent comparable full year since the introduction of the revised head injury policy. The radiology department computer was also interrogated, and a list of all head CTs and skull $x$ rays done during these periods was compiled. Total radiation doses were calculated for each period using typical radiation doses. ${ }^{13}$ The techniques used for skull $x$ rays and CTs during both periods were identical. Details of the patient's age, triage category, and subsequent destination were also available.

For the second part of the study, all patients who underwent head CT during period 2 were compared with an equal number of patients matched for age, triage category, and sex who also presented during period 2, and who did not undergo CT. The purpose of this was to define characteristics of patients who were thought to be at high risk of a significant head injury and therefore required CT. Hospital notes were retrieved for all patients in both groups, and details of their injury, treatment, and subsequent course were all entered on a specially designed proforma. Records were scanned to identify children who returned for unexpected review, or those who deteriorated or developed complications after initial discharge. As our hospital is the only admitting paediatric hospital in the area, all children in this category would have reattended here or would have been admitted here.

Finally, patients with normal and abnormal head CT results were compared. Positive and negative predictive values were calculated to determine the likelihood of an abnormal CT in the presence of each factor, and the likelihood of a normal CT in the absence of each factor. These values were calculated to determine the usefulness of each factor for predicting significant head injury. Comparison with the second part of the study enables factors that lead to CT being carried out, but which are poorly associated with an abnormal result, to be determined.

All information collected was analysed using Microsoft Excel. Fisher's exact test was used to compare categorical data and the Mann-Whitney $U$ test was used to compare non-parametric numerical data.

\section{RESULTS}

During period 1, 1535 patients over 1 year of age and less than 14 years of age presented to the emergency department, compared with 1867 patients in this age range during period 2 (table 2).

Figure 1 shows the distribution of head injuries by age during both time periods. The male:female ratio in period 1 was $64: 36 \%$ and the median age was 5.02 years (interquartile range 2.49 to 8.38 ). This compared to a male:female ratio of $67: 33 \%$ during period $2(p=0.42)$ with a median age of 4.87 years (IQR 2.53 to 8.56 years, $p=0.62$ ).

During period 1 there were 44 patients $(2.9 \%$ of the total head injuries between 1 and 14 years of age) allocated to triage category 1 or 2 (very serious and urgent categories), and 1491 patients $(97.1 \%)$ allocated to triage category 3 or 4 (less severe and less urgent). During period 2, equivalent figures were 50 patients $(2.7 \%)$ allocated to triage category 1 or 2 , and 1817 patients (97.3\%) allocated to triage category 3 or $4(\mathrm{p}=0.75)$.

In all, 340 patients $(22.1 \%)$ underwent a skull $x$ ray in period 1 compared to none in period 2; $328(96.5 \%)$ of these $x$ rays during period 1 were normal. Twelve $12 x$ rays were abnormal $(3.5 \%)$. Three of these were suspicious of a skull fracture and these patients went on to have a normal CT (receiving a dose of radiation twice). Of the nine who showed a definite skull fracture, two went on to have CT: one scan showed an $8 \mathrm{~mm}$ right frontal depressed skull fracture with a small underlying contusion, and one an isolated left parietal bone fracture with no intracranial injury. There were two
Table 1 1998-1999 and 2002-2003 guidelines for radiological imaging in head injuries (RHSCE emergency department head injury policy)

1998-1999 Radiological guidelines

Skull $x$ ray

History of head injury in a child of any age

Admission for observation and/or CT

Loss of consciousness more than 5 minutes

Amnesia

Persisting headache, vomiting, or lethargy

Coagulation or bleeding diathesis (also needs discussion with

haematology)

Immediate CT of head

GCS less than 14

Focal neurological signs

Seizure (focal or prolonged)

Signs of base of skull fracture

? Penetrating injury

? Depressed fracture

2002-2003 Radiological guidelines

Skull $x$ ray

Age less than 1 year and visible evidence of head injury

Age less than 1 year and suspicious history for NAl

Admission for observation and/or CT

Loss of consciousness more than 5 minutes

Amnesia

Persisting headache, vomiting or lethargy

Coagulation or bleeding diathesis (also needs discussion with

haematology)

Immediate CT of head

GCS less than 14

Focal neurological signs

Seizure (focal or prolonged)

Signs of base of skull fracture

? Penetrating injury

? Depressed fracture

CT, computed tomography; GCS, Glasgow coma scale score; NAI, nonaccidental injury; RHSCE, Royal Hospital for Sick Children, Edinburgh.

other significant head injuries (that is, patients with an abnormal brain CT) during period 1 (table 3 ). Both of these injuries occurred in patients undergoing CT as the initial imaging procedure.

In all, 16 patients ( $1.0 \%)$ underwent head CT during period 1 , resulting in four abnormal scans $(25.0 \%$ positive CT rate). Three scans showed intracranial injury, none of which required neurosurgical intervention. In comparison, 39 patients $(2.1 \%)$ underwent CT during period $2(\mathrm{p}=0.02)$. Of these 39 scans, 10 were abnormal $(25.6 \%$ of all head CTs in period 2). There were seven patients with underlying intracranial injury $(p=0.53)$, and two who required neurosurgical intervention $(p=0.30) \quad$ (table 3$)$. No patients received an ultrasound scan or magnetic resonance imaging (MRI) in the acute setting during either period, and all survived to hospital discharge.

There were 154 patients admitted during period 1 (10.1\%), compared with $203(10.9 \%)$ during period $2(p=0.43)$. Of those admitted during period 1 , five $(3.2 \%)$ went to the intensive care or high dependency unit and 149 (96.1\%) went to the ward. During the second period, 13 patients $(6.0 \%)$ went to the intensive care or high dependency unit and 190 $(93.6 \%)$ went to the ward $(p=0.23)$.

The total radiation dose for period 1 was $69.65 \mathrm{mSv}$, versus $78.0 \mathrm{mSv}$ for period 2. Radiation dose per head injury for period l was $0.045 \mathrm{mSv}$, versus $0.042 \mathrm{mSv}$ for period 2 . Statistical analysis of these data was not possible owing to the pattern of spread.

Figure $2 \mathrm{~A}$ and $2 \mathrm{~B}$ summarise the flow of patients through their investigations and management. There were no adverse 
Table 2 Comparison between the two study periods, one before and one after the abolition of skull $x$ rays

\begin{tabular}{|c|c|c|c|}
\hline & $1998-1999$ & 2002-2003 & p Value \\
\hline Head injuries $>1$ and $<14$ years & 1535 & 1867 & \\
\hline Male:female ratio & $975: 560$ & $1248: 619$ & $0.42 \dagger$ \\
\hline Median age (years) (IQR) & 5.02 (2.49 to 8.38$)$ & $4.87(2.53$ to 8.56$)$ & $0.62^{*}$ \\
\hline Urgent triage ( 1 or 2 ) & $44(2.9 \%)$ & $50(2.7 \%)$ & $075+$ \\
\hline Delayed triage ( 3 or 4 ) & $1491(97.1 \%)$ & $1817(97.3 \%)$ & $0.13 \top$ \\
\hline Skull $x$ rays & $340(22.1 \%)$ & 0 & \\
\hline Number of one view $x$ rays & $7(2.1 \%)$ & 0 & \\
\hline Number of two view $x$ rays & $233(68.5 \%)$ & 0 & \\
\hline Number of three view $x$ rays & $100(29.4 \%)$ & 0 & \\
\hline Normal skull $x$ rays & $328(96.5 \%)$ & 0 & \\
\hline Abnormal skull $x$ rays & $12(3.5 \%)$ & 0 & \\
\hline Skull $x$ ray total radiation dose & $37.65 \mathrm{mSv}$ & $0 \mathrm{mSv}$ & \\
\hline Head CT & $16(1.0 \%)$ & $39(2.1 \%)$ & $0.02 \uparrow$ \\
\hline Abnormal CT & $4(25.0 \%)$ & $10(25.6 \%)$ & $0.62 \dagger$ \\
\hline $\mathrm{CT}$ total radiation dose & $32.0 \mathrm{mSv}$ & $78.0 \mathrm{mSv}$ & \\
\hline Discharged & $1381(89.9 \%)$ & $1664(89.1 \%)$ & \\
\hline Admitted & $154(10.1 \%)$ & $203(10.9 \%)$ & $0.43 \uparrow$ \\
\hline ITU/HDU & $5(3.2 \%)$ & $13(6.0 \%)$ & \\
\hline Ward & $149(96.1 \%)$ & $190(93.6 \%)$ & $0.23 \dagger$ \\
\hline Total radiation dosage & $69.65 \mathrm{mSv}$ & $78.0 \mathrm{mSv}$ & \\
\hline Radiation dosage/head injury & $0.045 \mathrm{mSv}$ & $0.042 \mathrm{mSv}$ & \\
\hline Intracranial injuries & $3(0.20 \%)$ & $7(0.37 \%)$ & $0.53 \dagger$ \\
\hline Neurosurgical intervention & $0(0 \%)$ & $2(0.10 \%)$ & $0.30 \dagger$ \\
\hline
\end{tabular}

sequelae in either group attributable to either policy decisions.

For the second part of the study, the 39 patients who underwent CT during period 2 were compared with 39 patients who presented during period 2 but did not undergo CT, matched for age, triage category, and sex (table 4). Patients undergoing CT had a greater proportion of falls from a height of more than 1 metre and road traffic accidents, and a smaller proportion of falls of less than 1 metre. They also had a higher proportion of all types of neurological symptoms. Patients undergoing CT were less likely to have a scalp laceration. However, there was little difference with other injury type. The small number of patients in each category precluded further useful statistical analysis of these data.

Finally, patients with normal head CT in the period 20022003 were compared with those with abnormal CT in the same period (table 5). Of the 10 patients who had abnormal $\mathrm{CT}$, the commonest injury mechanisms were falling more than 1 metre (three patients) and being involved in a road traffic accident (six patients). Of the 29 patients having normal CT, the commonest injury mechanisms were a fall of less than 1 metre (nine patients) and a direct blow to the head (eight patients). Drowsiness (six patients) and loss of consciousness (five patients) were the commonest symptoms

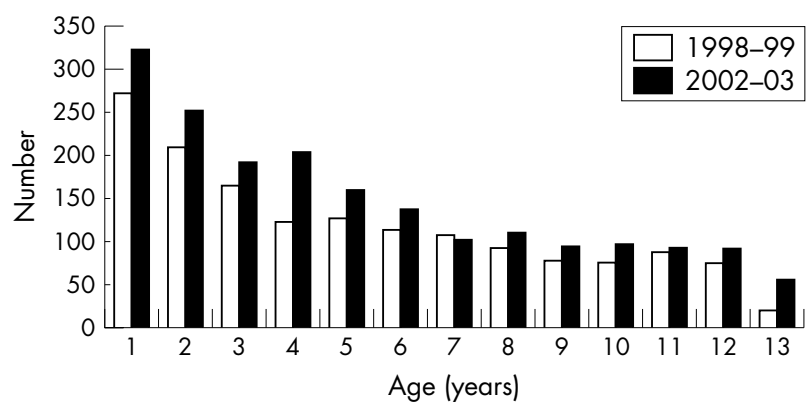

Figure 1 Distribution of head injuries by age. in the 10 patients with abnormal CT. All eight patients undergoing CT because of persistent vomiting had a normal scan.

Injuries found on examination were not predictive of abnormal CT, and all patients who had an abnormal scan received their scan within one hour. Again, the small number of patients precluded further statistical analysis.

\section{DISCUSSION}

The publication of guidelines by NICE and SIGN has signalled that a new approach to the management of head injury is needed. The publication by Lloyd et al has indicated that too many skull $x$ rays are being requested, with a significant unnecessary exposure to radiation by a large number of children. ${ }^{10}$ Any change in policy must, however, ensure that clinical safety is not being compromised. We introduced a change in radiographic policy for head trauma

Table 3 Details of patients sustaining significant head injuries during both study periods

1998-1999

Patient 1: Extensive middle cranial fossa fractures with some small areas of contusion

Patient 2: Comminuted, depressed right parietal fracture with underlying contusion

Patient 3: $8 \mathrm{~mm}$ right frontal depressed skull fracture with a small underlying contusion

\section{2-2003}

Patient 1: Right parietal fracture and extradural haematoma requiring craniotomy

Patient 2: Frontal fracture with associated subdural and extradural haematomas requiring craniotomy

Patient 3: Right parietal fracture with contusions

Patient 4: Right frontal fracture with contusion

Patient 5: Widespread cerebral contusions

Patient 6: Right frontal lobe subdural haematoma with contusions

Patient 7: Left parietal/occipital fracture with an underlying extradural haematoma 

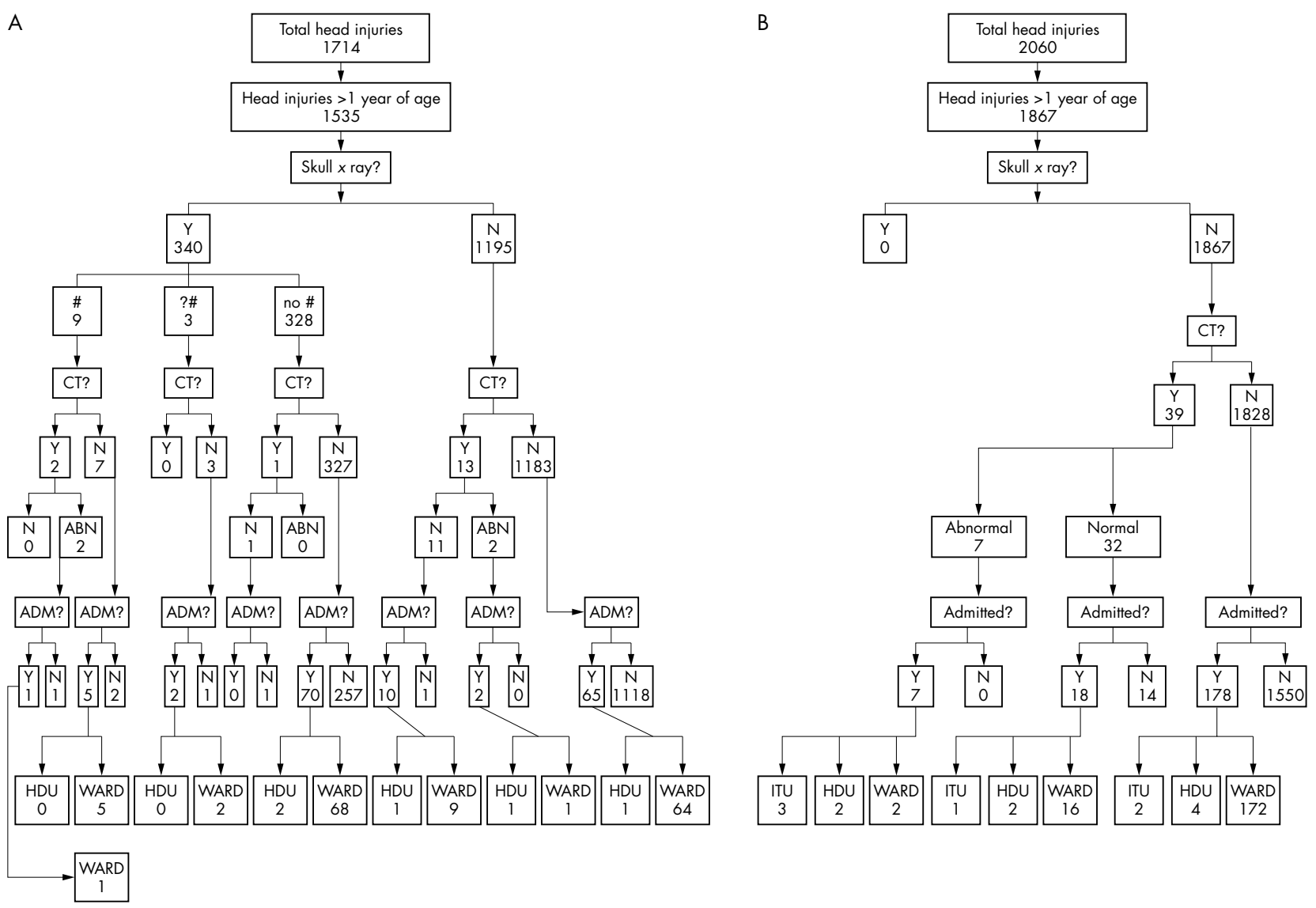

Figure 2 (A) Patient flow chart 1998-1999. (B) Patient flow chart 2002-2003.

after a careful examination of published reports, and ensured that child safety would be ensured by liberalising the option to admit, with a more liberal policy on CT request. The outcome from this change in policy is unique in that this is the first paper to evaluate such a policy. In addition it

Table 4 Comparison between 39 patients undergoing head CT in 2002-2003, and 39 age, sex, and triage category matched patients presenting during the same period

\begin{tabular}{lll} 
& $\begin{array}{l}\text { CT group } \\
\text { (n=39) }\end{array}$ & $\begin{array}{l}\text { Matched non-CT } \\
\text { group (n=39) }\end{array}$ \\
\hline Mechanism unknown & $2(5 \%)$ & $3(8 \%)$ \\
Fall $>1$ metre & $7(18 \%)$ & $5(13 \%)$ \\
Fall $<1$ metre & $10(26 \%)$ & $19(49 \%)$ \\
Fall down stairs & $2(5 \%)$ & 0 \\
Road traffic accident & $10(26 \%)$ & $1(3 \%)$ \\
Direct blow to head & $8(21 \%)$ & $11(28 \%)$ \\
Loss of consciousness & $9(23 \%)$ & $6(15 \%)$ \\
Seizure & $3(8 \%)$ & 0 \\
Vomiting & $8(21 \%)$ & $3(8 \%)$ \\
Drowsiness & $8(21 \%)$ & 0 \\
?NAl & $1(7 \%)$ & 0 \\
Amnesia & $2(5 \%)$ & 0 \\
Headache & $1(3 \%)$ & 0 \\
No abnormality & $10(26 \%)$ & $9(23 \%)$ \\
Facial haematoma & $4(10 \%)$ & $1(3 \%)$ \\
Facial laceration & $3(8 \%)$ & $5(13 \%)$ \\
Scalp haematoma & $10(26 \%)$ & $10(26 \%)$ \\
Scalp laceration & $1(3 \%)$ & $12(31 \%)$ \\
\hline Values are n (\%). & & \\
NAl, non-accidental injury. & & \\
\hline
\end{tabular}

anticipates the approach suggested by NICE and provides a framework within which other departments might alter policy.

Our results indicate that the abolition of skull $x$ rays in children aged 1 year and over prevented about 400 normal skull $x$ rays being done in period 2, with no detriment to any child in terms of missed injury. The percentage of children undergoing CT rose from $1.0 \%$ to $2.1 \%$ with no change in the positive CT pick up rate $(25.6 \%$ in period 2 compared with $25.0 \%$ in period 1). This compares favourably with figures from the American literature of $10 \%{ }^{9}$ There was no significant change in admission rate $(10.9 \% \quad v \quad 10.1 \%)$. However, there was a slight, but non-significant, increase in the percentage of patients being admitted to HDU and ITU $(6.0 \% v 3.2 \%)$. This reflected the greater number of significant head injuries that occurred during the second period.

There was a slight decrease in the radiation dose per head injury presentation ( $0.042 \mathrm{mSv}$ compared with $0.045 \mathrm{mSv}$ ). While there was a reduction in the radiation dose, there were a few patients in period 2 who received a much higher dose of radiation (those who underwent $\mathrm{CT}$ ), and a huge number who received no radiation. This fall in radiation dose would probably have been much more impressive if it were not for the slight increase in injury severity seen during period 2.

Comparison of patients with normal and abnormal CT suggests that the mechanism of injury is an important predictor of head injury severity. An abnormal CT was more likely in a patient who had sustained a fall greater than 1 metre or who had been involved in a road traffic accident. Falls less than 1 metre and direct blows to the head were both more likely to be associated with a normal CT scan. The 


\begin{tabular}{|c|c|c|c|c|}
\hline & $\begin{array}{l}\text { Normal CT } \\
(n=29)^{*}\end{array}$ & $\begin{array}{l}\text { Abnormal CT } \\
(n=10)^{*}\end{array}$ & $\begin{array}{l}\text { Positive } \\
\text { predictive value } \\
(\%)\end{array}$ & $\begin{array}{l}\text { Negative } \\
\text { predictive value } \\
\text { (\%) }\end{array}$ \\
\hline Mechanism unknown & $2(7 \%)$ & 0 & - & 73 \\
\hline Fall $>1$ metre & $4(14 \%)$ & $3(30 \%)$ & 43 & 78 \\
\hline Fall $<1$ metre & $9(31 \%)$ & $1(10 \%)$ & 10 & 69 \\
\hline Fall down stairs & $2(7 \%)$ & 0 & - & 73 \\
\hline Road traffic accident & $4(14 \%)$ & $6(60 \%)$ & 60 & 86 \\
\hline Direct blow to head & $8(28 \%)$ & 0 & - & 68 \\
\hline Loss of consciousness & $4(14 \%)$ & $5(50 \%)$ & 56 & 83 \\
\hline Seizure & $1(3 \%)$ & $2(20 \%)$ & 67 & 78 \\
\hline Vomiting & $8(28 \%)$ & 0 & - & 68 \\
\hline Drowsiness & $2(7 \%)$ & $6(60 \%)$ & 75 & 87 \\
\hline ?NAl & $1(3 \%)$ & 0 & - & 74 \\
\hline Amnesia & 0 & $2(20 \%)$ & 100 & 78 \\
\hline Headache & 0 & $1(10 \%)$ & 100 & 76 \\
\hline No abnormality & $9(31 \%)$ & $1(10 \%)$ & 10 & 69 \\
\hline Facial haematoma & $3(10 \%)$ & $1(10 \%)$ & 25 & 74 \\
\hline Facial laceration & $2(7 \%)$ & $1(10 \%)$ & 33 & 75 \\
\hline Scalp haematoma & $8(28 \%)$ & $2(20 \%)$ & 20 & 72 \\
\hline Scalp laceration & $1(3 \%)$ & 0 & - & $7 \overline{4}$ \\
\hline Within 1 hour & $8(28 \%)$ & $10(100 \%)$ & - & - \\
\hline $2-4$ hours & $9(31 \%)$ & 0 & - & - \\
\hline Same day & $2(7 \%)$ & 0 & - & - \\
\hline Next day & $5(17 \%)$ & 0 & - & - \\
\hline Same week & $3(10 \%)$ & 0 & - & - \\
\hline Next week & $2(7 \%)$ & 0 & - & - \\
\hline Prior to GA & $1(3 \%)$ & 0 & - & 74 \\
\hline Vomiting & $5(17 \%)$ & 0 & - & 71 \\
\hline Confusion & $2(7 \%)$ & $2(20 \%)$ & 50 & 77 \\
\hline Persistent headache & $7(24 \%)$ & 0 & - & 69 \\
\hline Boggy haematoma & $3(10 \%)$ & $1(10 \%)$ & 25 & 74 \\
\hline Reduced GCS & $5(17 \%)$ & $9(90 \%)$ & 64 & 96 \\
\hline Seizure & $1(3 \%)$ & $1(10 \%)$ & 50 & 76 \\
\hline Amnesia & $1(3 \%)$ & 0 & - & 74 \\
\hline Worrying mechanism & $1(3 \%)$ & 0 & - & 74 \\
\hline Collapse & $2(7 \%)$ & 0 & - & 73 \\
\hline Irritability & $1(3 \%)$ & $1(10 \%)$ & 50 & 76 \\
\hline Drowsiness & $6(20 \%)$ & $3(30 \%)$ & 33 & 77 \\
\hline Dizziness & $2(7 \%)$ & 0 & - & 73 \\
\hline ?Base of skull fracture & $2(7 \%)$ & $3(30 \%)$ & 60 & 80 \\
\hline Unknown & $2(7 \%)$ & 0 & - & 73 \\
\hline
\end{tabular}

exception to this may be injury caused by a blow to the head with a golf club, a relatively common childhood leisure pursuit in Scotland. In our series there were no serious injuries from this cause, though it has been shown in the past to be a risk factor for significant head injury. ${ }^{14}$

Patients who had an abnormal scan were more likely to have had a history of loss of consciousness or drowsiness. No patients with a history of vomiting had an abnormal scan. This has been shown previously to be a poor diagnostic indicator of significant head injury. ${ }^{15}$ Neurological observations were a more reliable predictor of intracranial injury than documented superficial injuries. This may reflect a failure to document superficial injuries accurately when the patient has neurological signs that are an immediate

\section{What is already known on this topic}

- Half of the one million patients treated annually for head injuries are children

- Present paediatric guidelines differ in their emphasis on the use of skull $x$ rays in head injured children, and guidelines from north America omit them altogether

- Detection of skull fractures in children is less helpful in guiding management than in adults indicator for $\mathrm{CT}$, and highlights a limitation of retrospective data collection.

All patients who had abnormal brain CT were scanned immediately. This suggests that, although it is well documented that intracranial injury can present some time after the initial injury, clinical suspicion is an extremely good predictor of head injury. This bears out the work of Sainsbury and Sibert. ${ }^{16}$ They determined in a Welsh population that all significant head injuries in children declared themselves as such within 6 hours of injury; 10 of 18 CT head scans $(55.6 \%)$ that were arranged within one hour of the patient attending the emergency department were positive. None of these immediate scans were in patients presenting late after sustaining their injury.

\section{What this study adds}

- Abolition of skull $x$ rays in children aged over 1 year resulted in no significant change in admission rate and a slight decrease in the radiation dose per head injury

- Skull $x$ rays can safely be abandoned in head injured children aged 1 to 14 , though this policy will be accompanied by an increase in the use of computed tomography 
Finally, nine of 14 patients (64\%) undergoing CT because of a reduced Glasgow coma score had an abnormal scan, while all patients in whom the CT indication was vomiting or persistent headache had a normal scan

\section{Conclusion}

This study shows that skull $x$ rays can successfully be abandoned in children aged 1 to 14 years with head injuries without any significant increase in admission rate, radiation dose per head injury, or missed intracranial injuries. We suggest that routine skull $x$ rays have no place in the paediatric emergency department for those children aged 1 year and over. Mechanism of head injury (falls of more than 1 metre and road traffic accidents carrying higher risk), a history of drowsiness or loss of consciousness, and a reduced score on the Glasgow coma scale are probably the most important indicators of serious head injury in children.

\section{ACKNOWLEDGEMENTS}

We thank Rik Smith at the Scottish Trauma Audit Group for statistical advice, and the radiographers in the $x$ ray department at RHSCE for help with retrieval of CT and $x$ ray data.

\section{Authors' affiliations}

M J Reed, J G Browning, T Beattie, Accident and Emergency

Department, Royal Hospital for Sick Children, Edinburgh, UK

A G Wilkinson, Radiology Department, Royal Hospital for Sick Children, Edinburgh

Competing interests: none declared

\section{REFERENCES}

1 Royal College of Surgeons of England. Report of the working party on the management of patients with head injury. London: Royal College of Surgeons of England, 1999

2 Jennet B. Epidemiology of head injury. Arch Dis Child 1998;78:403-6.

3 Strang I, Macmillan R, Jennet B. Head injuries in accident and emergency departments in Scotland. Injury 1978;10:154-9.

4 Jennett B. Epidemiology of head injury. J Neurol Neurosurg Psychiatry 1996:60:362-9.

5 Jennett B, MacMillan R. Epidemiology of head injury. BMJ 1981;282:101-7.

6 Sharples PM, Storey A, Aynsley-Green A, et al. Avoidable factors contributing to death of children with head injury. BMJ 1990;300:87-91.

7 National Institute for Clinical Excellence (NICE). Clinical guideline number 4. Head injury. triage, assessment, investigation and early management of head injuries in infants, children and adults. June, 2003.

8 Scottish Intercollegiate Guidelines Network (SIGN). Publication number 46. Early management of patients with a head injury. August, 2000 (ISBN $189989327 \mathrm{X}$.

9 Palchak MJ, Holmes JF, Vance CW, et al. A decision rule for identifying children at low risk for brain injuries after blunt trauma. Ann Emerg Med 2003;42:492-506.

10 Lloyd DA, Carty H. Predictive value of skull radiography for intracranial injury in children with blunt head injury. Lancet 1997;349:821-4.

11 Teasdale GM, Murray G, Anderson E, et al. Risks of acute traumatic intracranial haematoma in children and adults: implications for managing head injuries. BMJ 1990;300:363-7.

12 Mendelow AD, Teasdale G, Jennett B, et al. Risks of intracranial haematoma in head injured adults. BMJ 1983;287:1173-6.

13 Wall BF, Hart D. Revised radiation doses for typical $x$-ray examinations. Br J Radiol 1997;70:437-9.

14 Macgregor DM. Golf related head injuries in children. Emerg Med J 2002;19:576-7.

15 Brown FD, Brown J, Beattie TF. Why do children vomit after minor head injury? J Accid Emerg Med 2000;7:268-71.

16 Sainsbury CP, Sibert JR. How long do we need to observe head injuries in hospital? Arch Dis Child 1984;59:856-9. 